\title{
GGE Biplot Analysis for Thermo Sensitive Genic Male Sterile Lines of Rice (Oryza sativa L.) in Multi-Environment Trials
}

\author{
K. Sairekha ${ }^{1 *}$, S. Arumugachamy ${ }^{2}$, R. Suresh $^{3}$, R. Saraswathi ${ }^{1}$ and M. Kumar ${ }^{4}$ \\ ${ }^{1}$ Department of Rice, Tamil Nadu Agricultural University, Coimbatore-003, \\ Tamil Nadu, India \\ ${ }^{2}$ Rice Research Station, Ambasamudram, Tirunelvi, Tamil Nadu, India \\ ${ }^{3}$ Tamil Nadu Rice Research Institute, Aduthurai, Thanjavur district, Tamil Nadu, India \\ ${ }^{4}$ Department of Cotton, Tamil Nadu Agricultural University, Coimbatore-003, \\ Tamil Nadu, India \\ *Corresponding author
}

\section{A B S T R A C T}

\begin{tabular}{|l|}
\hline K e y w o r d s \\
TGMS, GGE biplot, \\
$\begin{array}{l}\text { Pollen sterility \%, } \\
\text { Spikelet sterility \% }\end{array}$ \\
\hline Article Info \\
\hline $\begin{array}{l}\text { Accepted: } \\
\text { xx December } 2017 \\
\text { Available Online: } \\
\text { xx January } 2018\end{array}$ \\
\hline
\end{tabular}

The genotype and genotype by environment biplot model is a valuable tool for visualization of multi-environment data. In this study, we investigated six traits for eight thermo-sensitive genic male sterile lines in rice across three environments viz., Aduthurai, Ambasamudram and Coimbatore. The first two principal components (IPC1 and IPC2) were used to create a two dimensional GGE biplot. In terms of agronomic performance, the study has identified the lines TNAU $14 \mathrm{~S}$ (G3) for days to $50 \%$ flowering and number of productive tillers; TNAU 45S for plant height and productive tillers; GDR $61 \mathrm{~S}$ and TNAU 39S for panicle length and GDR 70S, TNAU 95S for plant height and productive tillers respectively. The lines TNAU 45S (G6), TNAU 60S (G7) and TNAU 95S (G8) were stable for pollen sterility\% and spikelet sterility\%. among all the eight genotypes, TNAU 45S (G6) was identified as the best performing and stable line for pollen and spikelet sterility, more number of productive tillers and desirable height. The study has identified a new location viz., Aduthurai (E1) as the ideal environment for production of two line hybrids in rice apart from Coimbatore (E3).

\section{Introduction}

Rice is the primary source of food for more than half of the world's population. Hence, to feed the ever growing population, the targeted rice production of the world for the year 2030 is 771.02 million tonnes (Alexandratos and Bruinsma, 2012). One of the practical approaches to enhance the productivity and mitigating possible bottle necks to achieve food security is the development and cultivation of hybrids in rice. Different approaches are followed for development of hybrids namely the cytoplasmic genic male sterility system (CMS) and environment sensitive genic male sterility system (EGMS). Most of the hybrids released so far in rice are CMS based which needs specific restorer genes in the pollinator parents for complete restoration and thereby limits the usage of 
germplasm. Among the photoperiod sensitive (PGMS) and temperature sensitive (TGMS) genic male sterility systems that constitute EGMS, the TGMS system is more suitable for tropical countries like India. Besides, this system imposes no restrictions in the use of pollinators to identify heterotic combinations.

In this context, stable TGMS lines are needed that do not revert back to fertility during mild temperature fluctuations so that hybrid seed production can be taken up in a large scale in the desired environments. TGMS lines remain selectively male sterile at a specific range of temperatures and turn fertile at certain other temperatures. The wide range of temperature differences prevailing in Tamil Nadu favors TGMS system. So far, experimental hybrids based on TGMS could be taken up at Coimbatore during the sterile phase and TGMS line could be conveniently maintained during the fertile phase at high altitude of Gudalur, Nilgiris Dt. So, the primary objective of this study was to test the stability of sterility in TGMS lines to identify few more locations for hybrid seed production.

\section{Materials and Methods}

The experiments were conducted at three rice research stations namely Aduthurai (E1), Ambasamudram (E2) and Coimbatore (E3) during rabi/summer 2017. Eight TGMS lines, of which two lines GDR 61S and GDR 70S from HREC, Gudulur, TNAU and six lines viz., TNAU 14S, TNAU 18S, TNAU 39S, TNAU 45S, TNAU 60S and TNAU 95S from Paddy Breeding Station, Centre for Plant Breeding \& Genetics, TNAU, Coimbatore were used as experimental materials. Sowings were taken up on $13^{\text {th }}$ January, 2017 at all locations and thirty days old seedlings were transplanted in a spacing of $30 \times 20 \mathrm{~cm}$ with three replications. Data was recorded on six traits viz., days to fifty per cent flowering, plant height, number of productive tillers per plant, panicle length, spikelet sterility and pollen sterility. Pollen sterility $\%$ and spikelet sterility \% were scored based on the guidelines of SES, IRRI, 2001.

\section{Statistical analysis}

The six traits for eight genotypes in three environments were used to determine the effects of environment (E), genotype $(\mathrm{G})$ and their interactions. The data were graphically analyzed for interpreting GE interaction using the GGE biplot software (Yan, 2001). This methodology uses a biplot to show the factors ( $\mathrm{G}$ and GE) that are important in genotype evaluation and that are also the sources of variation in GE interaction analysis of MET data (Yan, 2001).

The graphs were generated based on (i) The polygon view of GGE biplot for the identification of winning genotypes and their mega environments by 'which-won-where' pattern (ii) Ranking of genotypes based on yield and stability performance (iii) Evaluation of genotypes related to an ideal genotypes (iv) Evaluation of environments related to ideal environments and (v) Relationship among environments.

\section{Results and Discussion}

Genotype $\times$ environment (GE) interaction refers to the different ranking of genotypes across environments that may complement the selection process and identify one or few genotypes for a target environment (Ebdon and Gauch, 2002; Gauch, 2006). GE interaction is also one of the most important reasons for the failure or decreased efficiency of breeding efforts to serve resource poor farmers in different areas (Ceccarelli, 1996; Kaya et al., 2006 and Mitrovic et al., 2012). Plant breeders perform multi-environment trials (MET) to select favourable genotypes based on both mean performance and stability 
and to determine whether a test environment is homogeneous or should be divided into various mega-environments (Gauch, 2006; Yan and Kang, 2003).

Yan et al., (2000) proposed a methodology known as genotype and genotype by environment (GGE) biplot for graphical display of GE interaction pattern of MET data with many advantages. The analysis considers both genotype $(\mathrm{G})$ and GE interaction effects and graphically displays GE interaction in a two way table (Yan, 2001). Thus GGE biplot based on principal component analysis (PCA) allows visual examination of the relationships among the test environments, genotypes and the GE interactions. In this present investigation, eight genotypes were evaluated for mean vs stability biplot analysis for four agronomic/ biometrical traits and two focused traits viz., pollen and spikelet sterility \%. The mean data across three locations for six traits in eight TGMS lines is provided in Table 1.

Mean performance and stability of the genotypes

In GGE biplot methodology, the estimation of performance of trait and stability of genotypes were done by using the average environment coordinate (AEC) method (Yan, 2001; Yan and Hunt, 2001). The line passing through the biplot origin, which is defined by the average PC1 and PC2 scores for all environments is called average environment coordinate (AEC). The line, which passes through the origin and is perpendicular to the AEC represents the stability of genotypes. Either direction away from the biplot origin, on the axis, indicates greater GE interaction and reduced stability. Ideal genotypes are those with both high mean performance and high stability. In this biplot, they will fall close to the origin and have shorter vector from the AEC. The biplot based on mean vs stability of eight TGMS lines for six traits individually are presented in Figure 1 .
Trait- wise interpretations reveal that the lines TNAU 14S (G3), TNAU 45S (G6), TNAU 95S (G8), GDR 61S (G1) and TNAU 18S (G4) and were the stable across locations, while TNAU 39S (G5) was the least stable for days to $50 \%$ flowering (Fig. 1a). On the other hand, among this group of stable lines, TNAU $45 \mathrm{~S}$, TNAU 14S, TNAU $18 \mathrm{~S}$ attained flowering earlier than the rest of the lines and by classification, they belong to the medium maturity group. The lines GDR $70 \mathrm{~S}$ and TNAU 95S were very late. However, the TNAU 14S (G3) had the highest stability among these five lines and considered as a best genotype for this trait.

Regarding plant stature, the lines viz., GDR $70 \mathrm{~S}$ (G2), TNAU 95S (G8) and TNAU 45S (G6) were the most stable lines in the order while TNAU 39S (G5) was the least stable (Fig. 1b). Since dwarf/semi dwarf stature is desirable in male sterile lines, TNAU $45 \mathrm{~S}$ is the most preferred genotype followed by GDR 70S. The GGE biplot for number of productive tillers indicated that the lines TNAU 14S (G3), TNAU 45S (G6) and TNAU 95S (G8) were stable. Among them TNAU 95S had high mean followed by TNAU $14 \mathrm{~S}$ and TNAU $45 \mathrm{~S}$ in close competition. The lines TNAU 39S (G5), GDR 61S (G1) and TNAU 60S (G7) were the most stable for panicle length, of which GDR 61S (G1) and TNAU 39S (G5) had higher mean for panicle length. The TGMS lines TNAU 45S (G6), TNAU 60S (G7) and TNAU 95S (G8) were the best performing genotypes in terms of pollen sterility\% along with high stability. Accordingly, the lines TNAU 14S (G3), TNAU 45S (G6), TNAU 60S (G7) and TNAU 95S (G8) were the best genotypes in case of spikelet sterility\%.

Genotypes with higher mean performance (except flowering and plant height) and stability are considered as desirable ones in stability analysis. In terms of agronomic performance, the study has identified the lines 
TNAU 14S (G3) for days to $50 \%$ flowering and number of productive tillers; TNAU 45S for plant height and productive tillers; GDR $61 \mathrm{~S}$ and TNAU 39S for panicle length and GDR 70S, TNAU 95S for plant height and productive tillers respectively. The lines TNAU 45S (G6), TNAU 60S (G7) and TNAU 95S (G8) were stable for pollen sterility\% and spikelet sterility\%. So, among all the eight genotypes, TNAU 45S (G6) was identified as the best performing and stable line for pollen and spikelet sterility, more number of productive tillers and desirable height.

\section{GGE biplot analysis for pollen and spikelet sterility \%}

\section{Polygon view GGE biplot}

In this biplot, a polygon was formed by connecting the vertex genotypes with straight lines and the rest of the genotypes were placed within the polygon. The polygon view of GGE biplots for pollen sterility\% and spikelet sterility $\%$ are presented in Figure 2. Three TGMS lines viz., TNAU 45S (G6), TNAU 60S (G7) and TNAU 95S (G8) fell in the first section and all of them were located at the vertex of this section and environment. Since the location Aduthurai (E1) fell in this section, these lines were winning genotypes for this environment. The environment Ambasamudram (E2) fell on the section 2 with four genotypes viz., GDR 61S (G1), GDR $70 \mathrm{~S}$ (G2), TNAU 14S (G3) and TNAU 18S (G4), but vertex genotypes (winning) for this location were GDR 70S (G2), TNAU 14S (G3) and TNAU 18S (G4). The line TNAU 39S (G5) formed the vertex of section 3 and it is considered as winning genotype for the environment Coimbatore (E3).

All three environments Aduthurai (E1), Ambasamudram (E2) and Coimbatore (E3) fell into section 1 in case of spikelet sterility\%. The first section accommodated four lines viz., TNAU 14S (G3), TNAU 45S (G6), TNAU 60S (G7) and TNAU 95S (G8), all located at the vertex, suggesting them as winning genotypes for all the three locations for spikelet sterility $\%$. On the other hand, the genotype GDR 61S (G1) which was located near the biplot origin, was less responsive than the vertex genotypes for both these parameters and showed intermediate/partial sterility. However, this mega-environment pattern needs to be verified through multi-year and environment trials as conducted in Wheat (Yan, 2000) and peanut (Casanoves et al., 2005 and Putto et al., 2008).

\section{Evaluation of genotypes relative to ideal genotype}

An interesting application of GGE biplot is the evaluation of genotype relative to ideal genotypes. The ideal genotypes as virtual genotype is one that has both high mean performance of that particular trait across test environments and is absolutely stable in performance (Yan and Rajcan, 2002; Yan and Kang, 2003). A genotype is more desirable if it closer to 'ideal genotype' (Kaya et al., 2006 and Mitrovic et al., 2012).

GGE biplot of ideal genotype and comparison of the genotypes with respect to the ideal genotype for pollen sterility\% and spikelet sterility $\%$ are presented in Figure $3 a$ and $3 b$ respectively.

The lines TNAU 45S (G6), TNAU 60S (G7) and TNAU 95S (G8) were closer to ideal genotype for the trait pollen sterility\%. Four lines viz., TNAU 14S (G3), TNAU 45S (G6), TNAU 60S (G7) and TNAU 95S (G8) closer to ideal genotype for spikelet sterility\% followed by GDR 61S (G1). It can be concluded that for both traits, the lines TNAU 45S (G6), TNAU 60S (G7) and TNAU 95S (G8) are more desirable. 
Int.J.Curr.Microbiol.App.Sci (2018) 7(1): 186-195

Table.1 Mean performance of eight TGMS lines in rice across three locations for six traits

\begin{tabular}{|c|c|c|c|c|c|c|c|c|c|c|c|c|c|c|c|c|c|c|c|}
\hline \multirow[t]{2}{*}{$\begin{array}{l}\text { S. } \\
\text { No }\end{array}$} & \multirow[t]{2}{*}{ Genotypes } & \multicolumn{3}{|c|}{$\begin{array}{l}\text { Days to } 50 \% \\
\text { flowering }\end{array}$} & \multicolumn{3}{|c|}{ Plant height (cm) } & \multicolumn{3}{|c|}{$\begin{array}{l}\text { Productive } \\
\text { tillers per plant }\end{array}$} & \multicolumn{3}{|c|}{$\begin{array}{l}\text { Panicle length } \\
(\mathrm{cm})\end{array}$} & \multicolumn{3}{|c|}{$\begin{array}{c}\text { Pollen } \\
\text { sterility } \%\end{array}$} & \multicolumn{3}{|c|}{$\begin{array}{c}\text { Spikelet } \\
\text { sterility \% }\end{array}$} \\
\hline & & E1 & E2 & E3 & E1 & E2 & E3 & E1 & E2 & E3 & E1 & E2 & E3 & E1 & E2 & E3 & $\mathbf{E 1}$ & E2 & E3 \\
\hline 1 & GDR 61S & 120 & 108.2 & 118 & 96.6 & 81.8 & 92.8 & 8 & 14.6 & 10.8 & 24.8 & 23.4 & 23.8 & 20 & 81.2 & 20 & 58.0 & 98.6 & 79.04 \\
\hline 2 & GDR 70S & 130 & 111.4 & 127 & 110.0 & 80.2 & 84.5 & 7 & 19.0 & 19.3 & 26.5 & 26.0 & 21.0 & 0 & 93.4 & 0 & 15.0 & 98.0 & 5.0 \\
\hline 3 & TNAU $14 \mathrm{~S}$ & 113 & 109.4 & 108 & 75.0 & 74.2 & 75.0 & 11 & 17.4 & 16.8 & 23.8 & 24.6 & 23.6 & 100 & 100 & 100 & 90.0 & 100 & 100 \\
\hline 4 & TNAU $18 \mathrm{~S}$ & 112 & 107.6 & 113 & 107.0 & 72.8 & 84.8 & 9 & 19.6 & 11.8 & 22.5 & 24.0 & 21.7 & 0 & 89.0 & 0 & 36.0 & 100 & 28.0 \\
\hline 5 & TNAU 39S & 112 & 113.6 & 94 & 94.2 & 80.4 & 70.2 & 13 & 21.4 & 15.5 & 23.5 & 26.0 & 20.2 & 0 & 80.8 & 42 & 27.0 & 79.6 & 76.6 \\
\hline 6 & TNAU 45S & 110 & 111.4 & 106 & 82.3 & 76.6 & 80.2 & 14 & 15.8 & 15.0 & 22.4 & 26.6 & 23.2 & 100 & 100 & 100 & 100 & 100 & 100 \\
\hline 7 & TNAU $60 \mathrm{~S}$ & 95 & 109.0 & 108 & 78.5 & 63.6 & 74.5 & 12 & 15.2 & 14.0 & 22.5 & 22.8 & 19.75 & 100 & 100 & 100 & 100 & 100 & 100 \\
\hline 8 & TNAU 95S & 124 & 119.0 & 117 & 110 & 88 & 94.4 & 17 & 18.2 & 19.2 & 29.2 & 28.2 & 24.3 & 100 & 100 & 100 & 100 & 100 & 100 \\
\hline
\end{tabular}


Fig.1 GGE biplot graph based on mean vs stability for six traits in rice TGMS lines

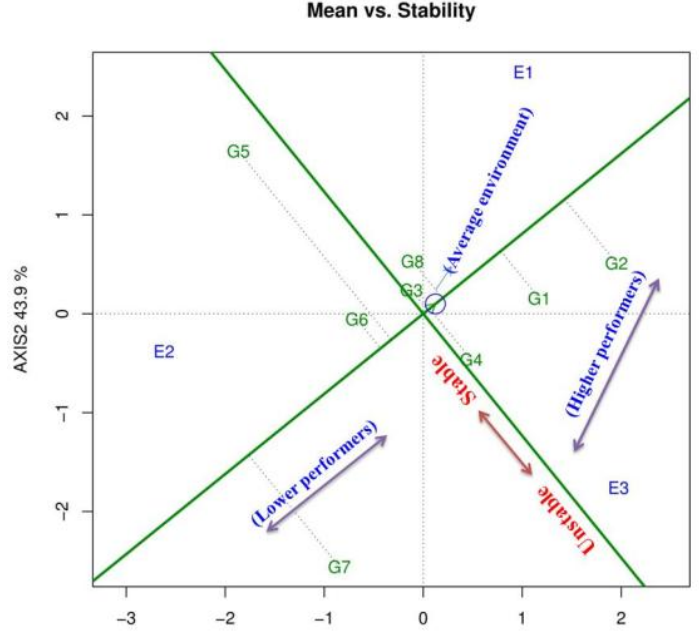

b) Plant height

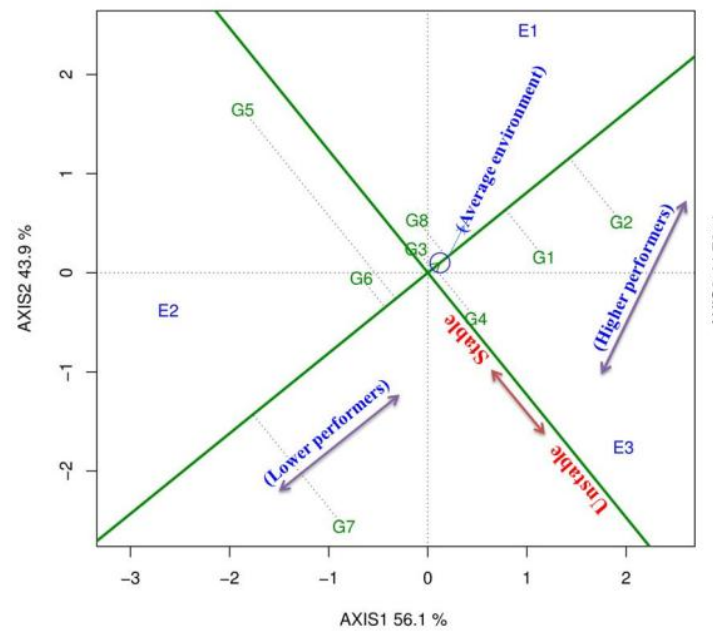

c) Number of productive tillers

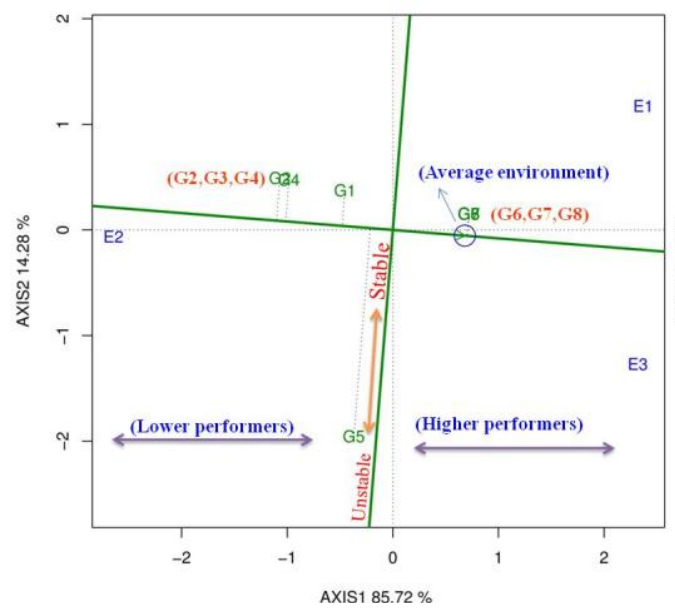

e) Pollen sterility \%

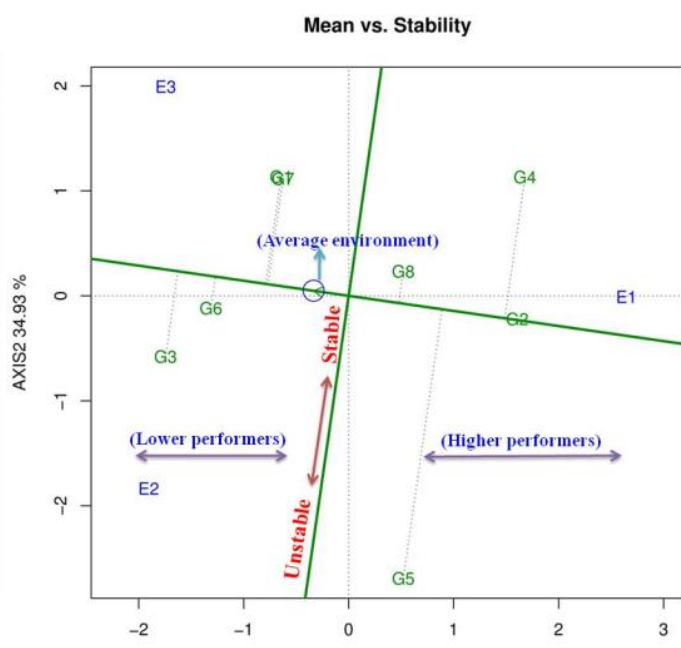

a) Days to $50 \%$ flowering

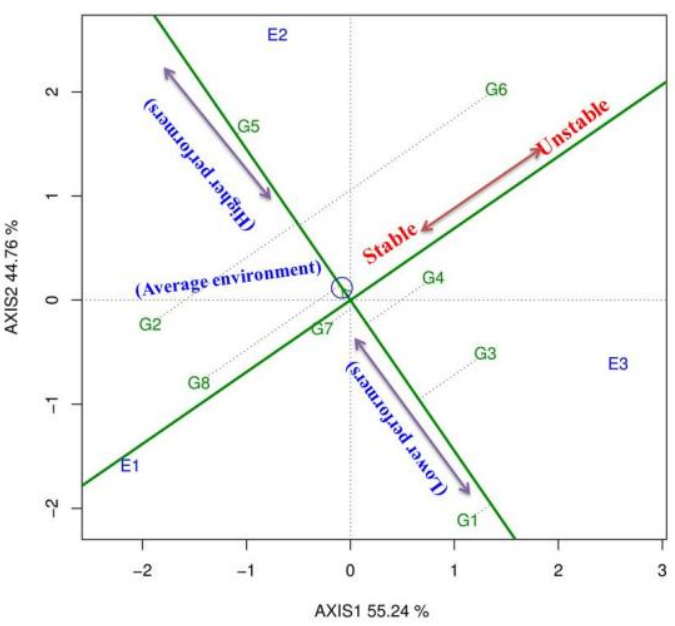

d) Panicle length

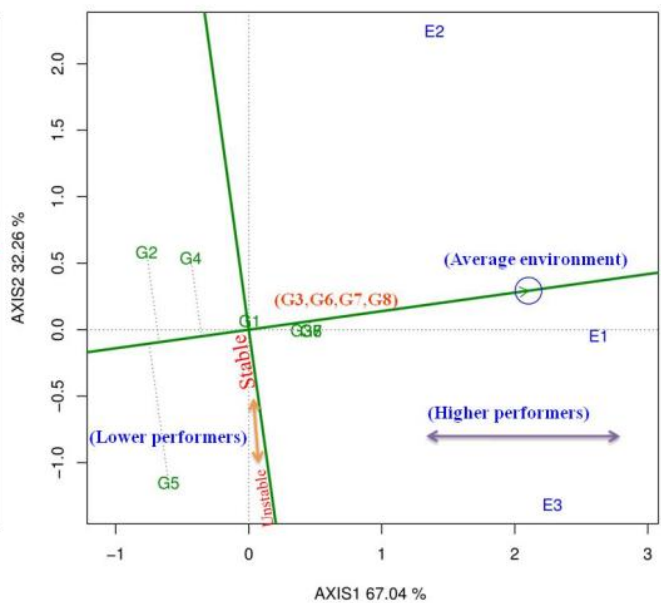

f) Spikelet sterility $\%$ 
Fig.2 Polygon view of GGE biplot for a) pollen sterility $\%$ and b) spikelet sterility $\%$ in rice TGMS lines

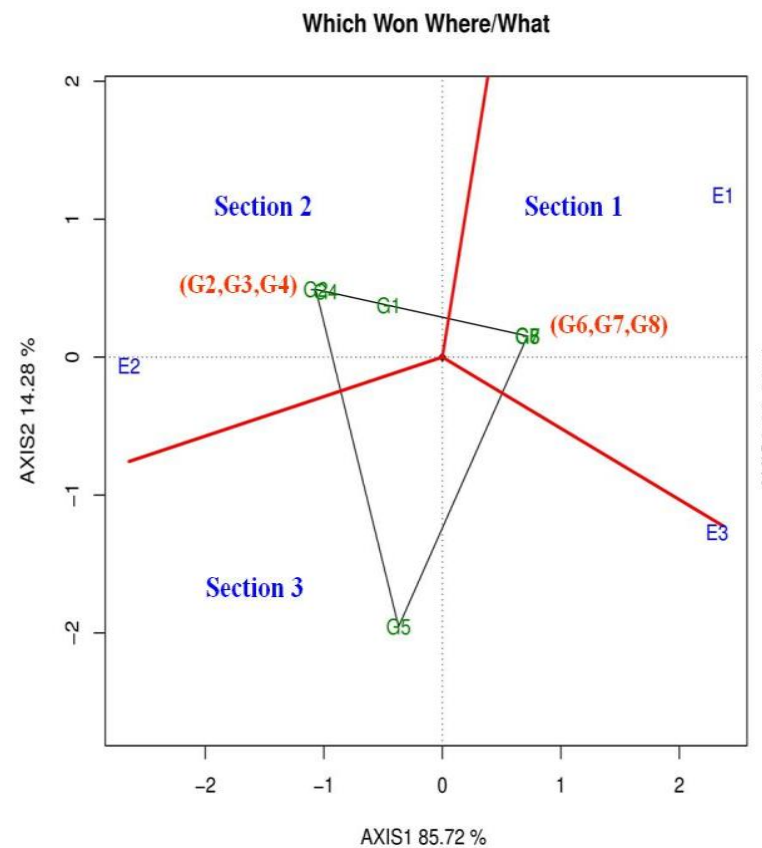

a) Pollen sterility $\%$

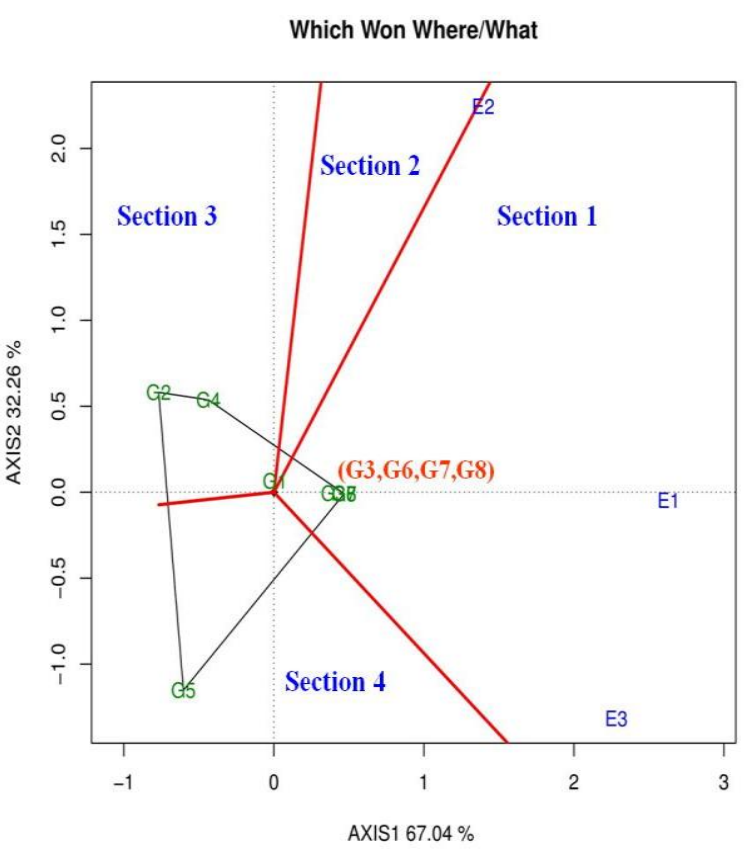

b) Spikelet sterility \%

Fig.3 Ranking of rice genotypes based on ideal genotype for a) pollen sterility $\%$ and b) spikelet sterility \%

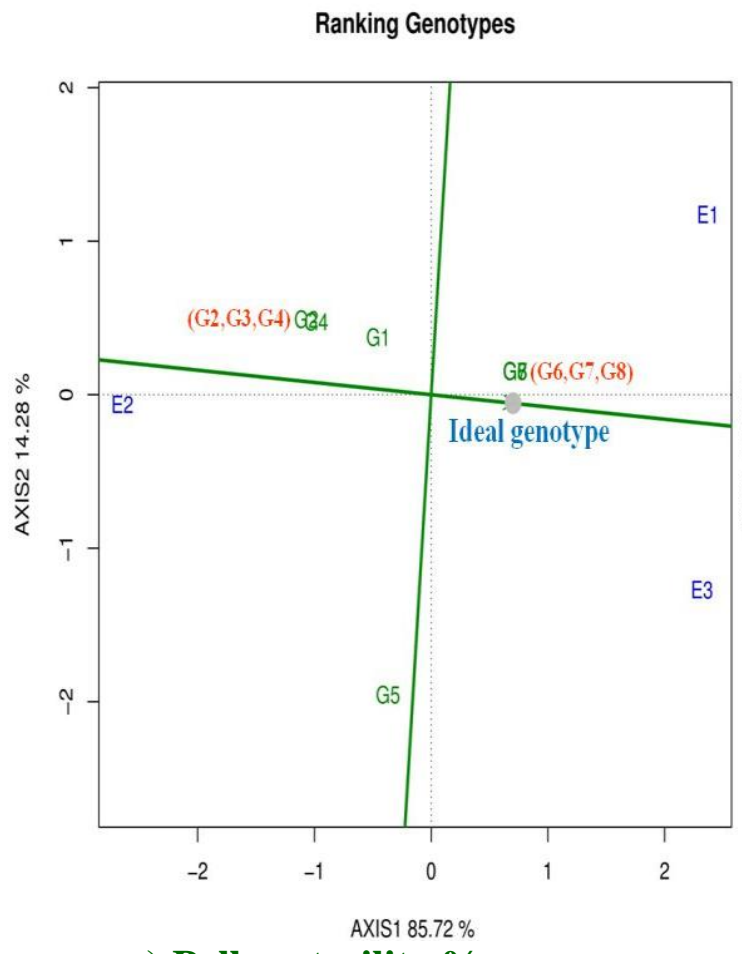

a) Pollen sterility \%
Ranking Genotypes

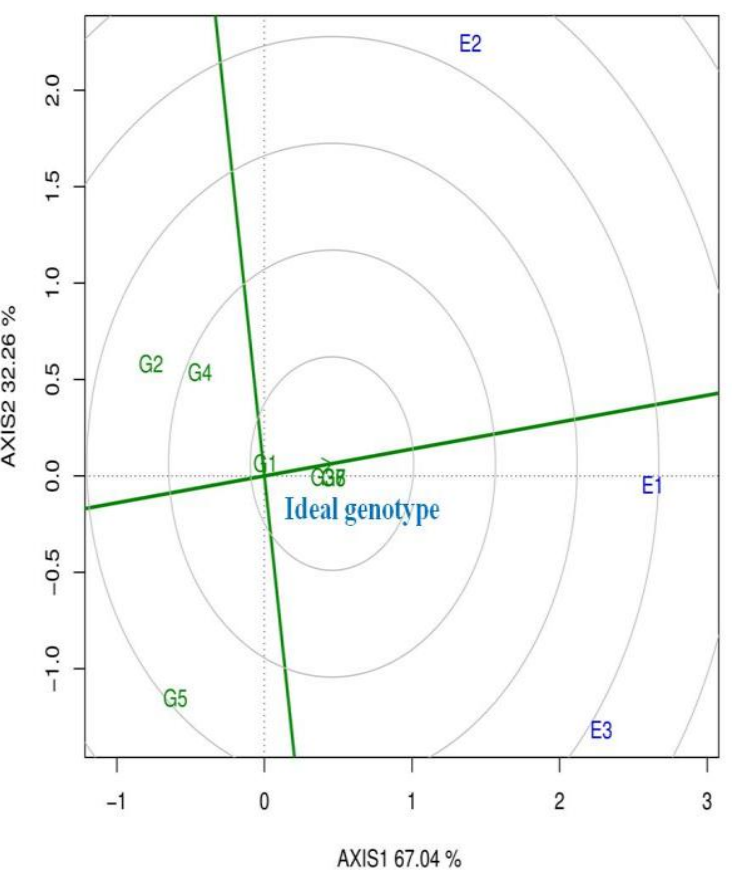

b) Spikelet sterility \% 
Fig.4 Ranking of environments based on ideal environment for a) pollen sterility\% and b) spikelet sterility\% in rice TGMS lines

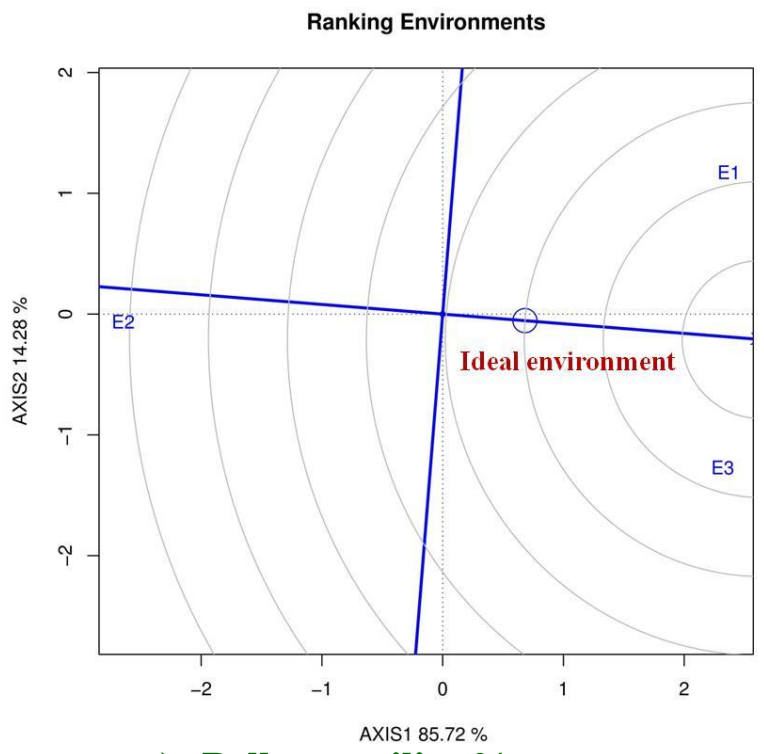

a) Pollen sterility \%

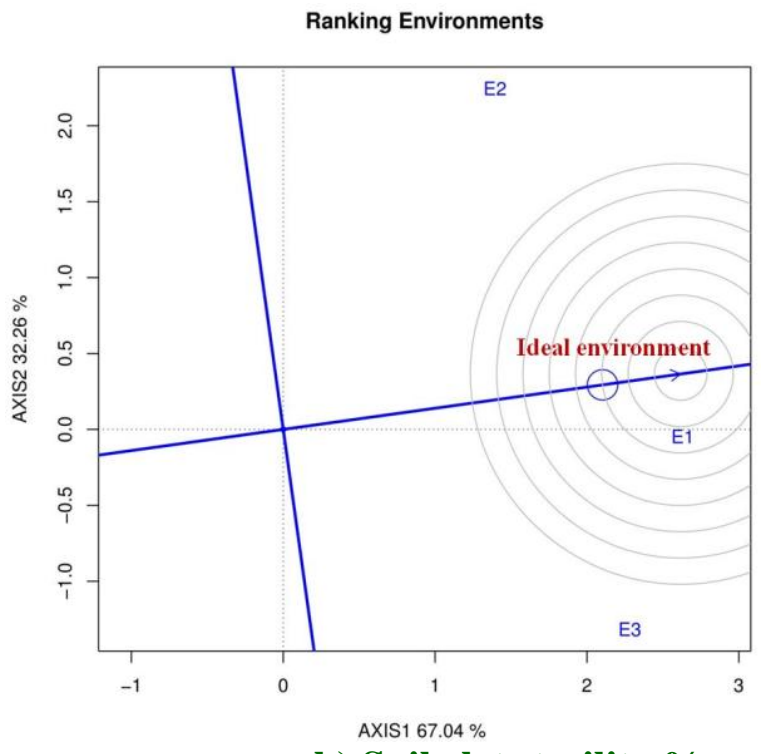

b) Spikelet sterility \%

Fig.5 GGE biplot for evaluating relationship between environments for a) pollen sterility $\%$ and b) spikelet sterility \% in rice

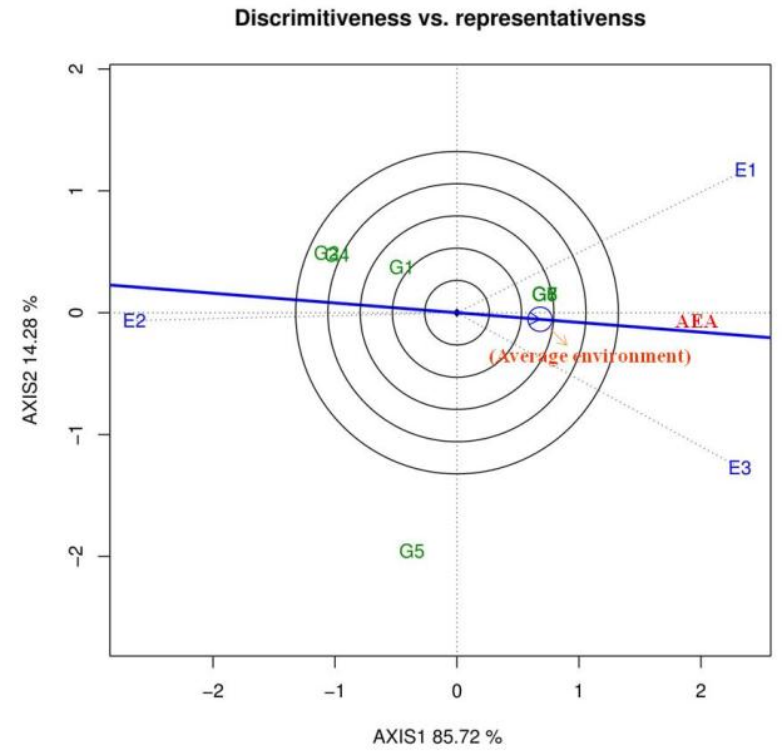

a) Pollen sterility \%

Evaluation of environments relative to ideal environment

This analysis gives information on the ideal environment for these two important traits. The

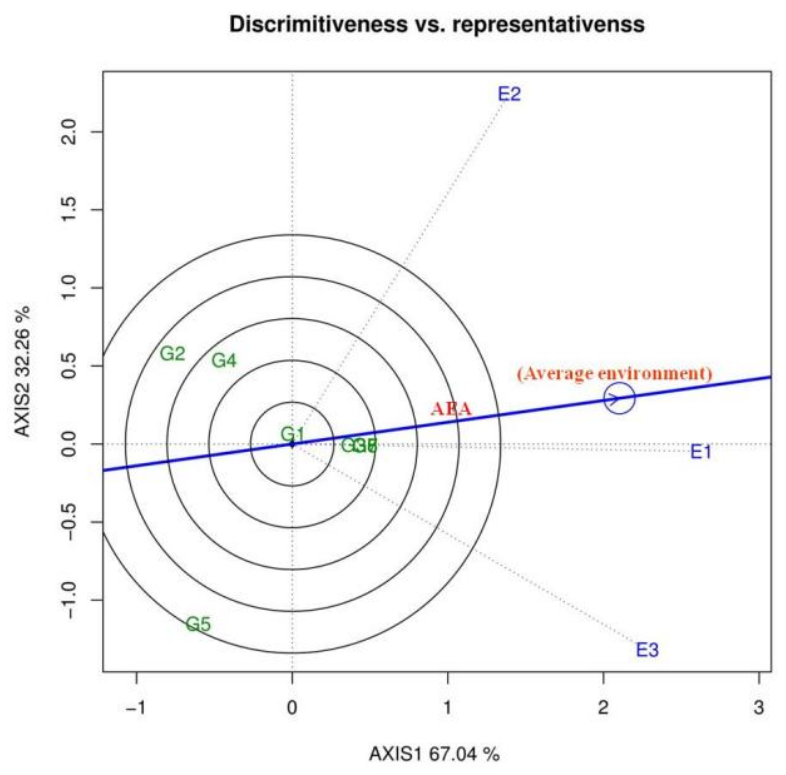

b) Spikelet sterility \%

environment Aduthurai (E1) was placed nearer to the ideal environment followed by Coimbatore (E3) for pollen sterility\% (Fig 4a), while for spikelet sterility, only Aduthurai (E1) was very close to ideal environment and other 
two locations were far away from the ideal environment (Fig. 4b).

This suggested that Aduthurai (E1) which was very close to the ideal environment in both the cases was very stable and suitable for all genotypes.

Similar studies were also taken up to identify ideal genotype and ideal environment by Rakshit et al., (2012) in sorghum for days to flowering, harvest index, grain yield and fodder yield; Akter et al., (2015) in rice for yield and Tariku (2017) in rice for days to maturity, panicle length, plant height, number of grains per panicle, number of filled grains per panicle, thousand grain weight and grain yield.

\section{Relationship among environments}

The environment vectors are lines that connect the biplot origin and the markers of test environment and the angle between them is related to the correlation coefficient (Kroonenberg, 1995). Locations with small angle between them were positively correlated and these provide similar information on genotypes. Distance between two environments measures their ability in discriminating the genotypes. GGE biplot for relationship among test environments for pollen sterility $\%$ and spikelet sterility\% are presented in Fig 5a and $5 b$.

Environment Ambasamudram (E2) showed inverse relationship to that of environments Aduthurai (E1) and Coimbatore (E3) for pollen sterility\% as the vector showed obtuse angle. Environment Aduthurai (E1) is correlated with Coimbatore (E3) with acute angle between them in case of pollen sterility\%. The same trend was noticed for spikelet sterility\% in which Aduthurai (E1) is closer to Coimbatore (E3) than Ambasamudram (E2).

In the Fig. 5, the 'average environment' is represented by a small circle on the AEA. Environments with small angles with AEA are the most representative of the average test environments. Thus, environment Aduthurai (E1) in case of spikelet sterility\% was closest to the average environment and is the best representative for this trait.

In the present study, the TGMS line TNAU 45S (G6) was identified as the best performing and stable line for pollen and spikelet sterility with desirable agronomic characters like more number of productive tillers and desirable height and can be used for production of two line hybrids over the three locations. The lines TNAU 45S (G6), TNAU 60S (G7) and TNAU 95S (G8) were stable for pollen and spikelet sterility\%. Two other lines viz., TNAU 60S (G7) and TNAU 95S (G8) were stable for the interested traits namely pollen and spikelet sterility\%. In terms of agronomic performance, they have limitations because TNAU 60S which exhibited stability for panicle length alone had short panicles while TNAU 95S due to its tallness and late duration coupled with stable expression of these traits poses certain limitations as a female line in hybrid breeding. The line TNAU 14S showed 100\% spikelet sterility and was agronomically desirable with dwarf height, medium duration and more tillering but exhibited pollen fertility to a tune of $10 \%$ in the favorable environment, Aduthurai (E1). Hence it needs further confirmation. The study has thus identified a new location viz., Aduthurai (E1) in addition to Coimbatore (E3) as best environment for production of two line hybrids in rice.

\section{References}

Akter, A., M. Jamil Hasan, Umma Kulsum, M. H. Rahman, M. Khatun and M. R. Islam. 2015. GGE biplot analysis for yield stability in multi-environment trails of promising hybrid rice (Oryza sativa L.). Bangladesh Rice J. 19(1): 1-8.

Alexandratos, N and J. Bruinsma, 2012. World Agriculture towards 2030/2050. ESA Working Paper No. 12-03. Agricultural Development Economics Division, FAO, Rome, Italy.

Bradu, D and K. R. Gabriel. 1978. 
Technometrics. 20: 47-68.

Casanoves, F., R. Macchiavelli and M. Balzarini. 2005. Error variation in multienvironment peanut trials. Crop Sci. 45: 1927-1933

Ceccarelli, S. 1996. Adaptation to low or high input cultivation. Euphytica. 92: 203-214.

Ebdon, J.S. and H. G. Gauch. 2002. Additive mean effect and multiplicative interaction analysis of national turfgrass performance trials. 1. Interpretation of genotype $\mathrm{x}$ environmental interaction. Crop Sci. 42, 489-496.

Gauch, H. G. 2006. Statistical analysis of yield trials by AMMI and GGE. Crop Sci. 46:1488-1500.

Kaya, Y. M., Akcura and S. Taner. 2006. GGEbiplot analysis of multi-environment yield trails in bread wheat. Turk. J. Agric. 30: 325-337.

Kroonenberg, P. M. 1995. Introduction to biplots for $G \times$ E tables. Dept. of Mathematics, Res. Rep. 51. Univ. of Queensland, Australia.

Mitrovic, B., D. Stanisavlijevi, S. Treski, M. Stojakovic, M. Ivanovic, G. Bekabac and M. Rajkovic. 2012. Evaluation of experimental maize hybrids tested in mutli-location trails using AMMI and GGE biplot analysis. Turkish J. Field Crops. 17(1): 35-40.

Putto, W., A. Patanothai, S. Jogloy and Hoogenboom. 2008. Determination of mega-environments for peanut breeding using the CSM-CROPGRO-Peanut model. Crop Sci. 48: 973-982.

Rakshit, S., K. N. Ganapathy, S. S. Gomashe, A. Rathore, R. B. Ghorade, M. V. Nagesh Kumar, K. Ganesmurthy, S. K. Jain, M.
Y. Kamtar, J. S. Sachan, S. S. Ambekar, B. R. Ranwa, D. G. Kanawade, M. Balusamy, D. Kadam, A. Sarkar, V. A. Tonapi and J. V. Patil. 2012. GGE biplot analysis to evaluate genotype, environment and their interactions in sorghum multi-location data. Euphytica. 185: 465-479.

Standard Evaluation System, IRRI, 2001

Tariku, S. 2017. Evaluation of Upland Rice Genotypes and Mega Environment Investigation Based on GGE-Biplot Analysis. J Rice Res. 5: 183.

Yan, W and I. Rajcan. 2002. Biplot analysis of test sites and trait relations of soyabean in Ontario. Crop Sci. 42: 11-20.

Yan, W and L. A. Hunt. 2001. Interpretation of genotype $\times$ environment interaction for winter wheat yield in Ontario. Crop Sci. 41: 19-25.

Yan, W and M. S. Kang. 2003. GGE biplot analysis: a graphical tool for breeders, Geneticists and Agronomists. 1st Edn., CRC Press LLC., Boca Raton, Florida, pp: 271.

Yan, W. 2001. GGE biplot a windows application for graphical analysis of multi-environment trial data and other types of two way data. Agron. J. 93: 1111-1118.

Yan, W., and M. S. Kang. 2003. GGE biplot analysis: a graphical tool for breeders, geneticists, and agronomists. CRC Press, Boca Raton.

Yan, W., L. A. Hunt, Q. Sheng and Z. Szlavnics. 2000. Cultivar evaluation and mega-environment investigation based on GGE biplot. Crop Sci. 40:597-605.

\section{How to cite this article:}

Sairekha, K., S. Arumugachamy, R. Suresh, R. Saraswathi and Kumar, M. 2018. GGE Biplot Analysis for Thermo Sensitive Genic Male Sterile Lines of Rice (Oryza sativa L.) in MultiEnvironment Trials. Int.J.Curr.Microbiol.App.Sci. 7(01): 186-195. doi: https://doi.org/10.20546/ijcmas.2018.701.021 